\title{
Isothermal Phase Equilibria for Methane + Ethane + Water Ternary System Containing Gas Hydrates
}

\author{
Shunsuke Hashimoto, Arata Sasatani, Yuuki Matsui, Takeshi Sugahara and Kazunari Ohgaki*
}

\begin{abstract}
Division of Chemical Engineering, Graduate School of Engineering Science, Osaka University, 1-3, Machikaneyama, Toyonaka, Osaka 560-8531, Japan
\end{abstract}

\begin{abstract}
It is well known that methane + ethane mixed-gas hydrate exhibits the structural phase transition between structure-I and -II although both of pure guest species form the structure-I hydrate at certain pressures and temperatures (Subramanian, Kini, Dec and Sloan, Chem. Eng. Sci., vol. 55, pp. 1981-1999, June 2000). In the present study, isothermal phase equilibrium (pressure - composition) relations for the methane + ethane mixed-gas hydrate system were measured accurately at $279.1 \mathrm{~K}-288.1 \mathrm{~K}$. In addition, the equilibrium composition in the mixed-gas hydrate phase was investigated by mass and volume balances analysis. At all temperature conditions, the equilibrium curves exhibit discontinuity around given equilibrium compositions (water free), which supports that the structural phase transition occurs. The pressure of structural transition point increases as temperature rises, and the mole fractions of both hydrate phases at the structural transition point are almost independent of temperature.
\end{abstract}

\section{INTRODUCTION}

Gas hydrates are one of clathrate inclusion compounds, which are stabilized by guest species in the cavity of cages. These hydrate cages are composed of the hydrogen-bonded water molecules. There are well-known several types of hydrate unit-cell structures; structure-I (s-I), -II (s-II), and -H $(\mathrm{s}-\mathrm{H})$. All the unit lattices have a common hydrate cage (Scage) of pentagonal dodecahedron $\left(5^{12}\right)$. In addition, the s-I and -II have one other type of cage (M-cage, $5^{12} 6^{2}$ or L-cage, $5^{12} 6^{4}$, respectively), whose size is larger than the S-cage. The hydrate structure mainly depends on the size, shape, and physical properties of enclathrated guest-species.

Gas hydrates have become the object of much attention because enormous quantities of natural gas in the form of gas hydrate exist in the permafrost regions and the sediments under the deep-ocean floor. Since then, various studies of the stability and structure of gas hydrates have ever been performed by many scientists in the world. The natural gas is usually composed of a mixture of methane $\left(\mathrm{CH}_{4}\right)$ and some impurities of ethane $\left(\mathrm{C}_{2} \mathrm{H}_{6}\right)$, propane $\left(\mathrm{C}_{3} \mathrm{H}_{8}\right)$, carbon dioxide $\left(\mathrm{CO}_{2}\right)$, ethylene $\left(\mathrm{C}_{2} \mathrm{H}_{4}\right)$, and so on. In general, the composition of natural gas depends on the source of gas hydrates. Therefore, it is necessary for the exploitation of natural-gas hydrate and applied techniques using gas hydrates to reveal the phase behavior of mixed gas hydrate systems including $\mathrm{CH}_{4}$.

So far, the structural transition of mixed-gas hydrates between s-I and s-II hydrates for the $\mathrm{CH}_{4}+\mathrm{C}_{2} \mathrm{H}_{6}$ [1-3], $\mathrm{CH}_{4}$ + cyclopropane $\left(c-\mathrm{C}_{3} \mathrm{H}_{6}\right)$ [4], $\mathrm{CH}_{4}+$ tetrafluoromethane $\left(\mathrm{CF}_{4}\right)$ [5] mixed-gas hydrate systems have been reported, while each species generates the s-I hydrate by itself.

*Address correspondence to this author at the Division of Chemical Engineering, Graduate School of Engineering Science, Osaka University, 1-3, Machikaneyama, Toyonaka, Osaka 560-8531, Japan; Fax: +81-6-68506290; E-mail: ohgaki@cheng.es.osaka-u.ac.jp
Subramanian, Kini, Dec and Sloan [1], Subramanian, Ballard, Kini, Dec and Sloan [2] and Ballard and Sloan [3] have already reported that the hydrate structural transition between the s-I and -II in a certain composition region for the $\mathrm{CH}_{4}+\mathrm{C}_{2} \mathrm{H}_{6}$ mixed-gas hydrate system. They have also revealed the cage occupancies of $\mathrm{CH}_{4}$ and $\mathrm{C}_{2} \mathrm{H}_{6}$ molecules by use of nuclear magnetic resonance (NMR) or laser Raman spectroscopic analyses. These findings are very important and useful for the related processes using gas hydrates. However, the isothermal phase behavior for the $\mathrm{CH}_{4}+\mathrm{C}_{2} \mathrm{H}_{6}$ mixed-gas hydrate system has been reported by only thermodynamic simulation. There is a lack of information about the thermodynamic stability of $\mathrm{CH}_{4}+\mathrm{C}_{2} \mathrm{H}_{6}$ mixed-gas hydrate. The phase behavior of the $\mathrm{CH}_{4}+\mathrm{C}_{2} \mathrm{H}_{6}$ mixed-gas hydrate system needs to be determine experimentally instead of numerical results.

In the present study, isothermal phase equilibrium (pressure - composition) relations for the $\mathrm{CH}_{4}+\mathrm{C}_{2} \mathrm{H}_{6}$ mixed-gas hydrate system were measured at $279.1 \mathrm{~K}, 283.1 \mathrm{~K}$, and $288.1 \mathrm{~K}$ by means of gas chromatography. In addition, the equilibrium composition in the mixed-gas hydrate phase was estimated from mass and volume balances. The structure of mixed-gas hydrate under three-phase equilibrium states was confirmed by use of in situ Raman micro-spectroscopy.

\section{EXPERIMENTAL}

\section{Materials}

Research grade $\mathrm{CH}_{4}$ (mole fraction purity 0.9999 ) was obtained from the Neriki Gas Co., Ltd. Research grade $\mathrm{C}_{2} \mathrm{H}_{6}$ (mole fraction purity 0.999 ) was purchased from Takachiho Trading Co., Ltd. The distilled water was obtained from the Wako Pure Chemical Industries, Ltd. All of them were used without further purifications.

\section{Apparatus}

The experimental apparatus for the phase equilibrium measurements was the same as the previous one $[4,6]$. The 
high-pressure cell made of stainless steel had an inner volume of $c a .100 \mathrm{~cm}^{3}$. The maximum working pressure was 20 $\mathrm{MPa}$. The cell had a set of sapphire windows for visually observing the phase behavior. The system temperature was controlled by the thermostated water circulating from a thermocontroller through the jacket in the cell. The contents were agitated using an up-and-down mixing bar driven by an exterior permanent magnetic ring.

The high-pressure optical cell for the Raman spectroscopic analysis had a pair of sapphire windows on both the upper and lower sides. This high-pressure optical cell is the same as previous one [7]. The thermostated water was circulated constantly in the exterior jacket of the high-pressure optical cell. A ruby ball was enclosed into the high-pressure optical cell. The contents were agitated by the ruby ball, which was rolled around by the vibration of vibrator from outside.

The system temperature was measured within an uncertainty of $0.02 \mathrm{~K}$ using a thermistor probe (Takara D-632), which was inserted into a hole in the cell wall. The probe was calibrated with a Pt resistance thermometer defined by ITS-90. The system pressure was measured by a pressure gage (Valcom VPRT) calibrated by RUSKA quartz Bourdon tube gage (Direct Reading Pressure Gage, series 6000) with an estimated maximum uncertainty of $0.01 \mathrm{MPa}$.

\section{Procedures}

\section{Phase Equilibrium Measurements}

The gas mixture of $\mathrm{CH}_{4}$ and $\mathrm{C}_{2} \mathrm{H}_{6}$ prepared at a desired composition was introduced into the evacuated high-pressure cell. The content was pressurized up to the desired pressure by supplying distilled water successively and then continuously agitated using the up and down mixing bar. After the formation of gas hydrates, the system temperature was kept constant to establish the three-phase coexisting state of hydrate + aqueous solution + gas for at least more than one day. The phase behavior was observed directly through the window. After reaching the equilibrium state of three-phase coexistence, a small amount of gas and aqueous phases were sampled for composition analysis. The equilibrium compositions (water free) in the gas and aqueous phases were analyzed for $\mathrm{CH}_{4}$ and $\mathrm{C}_{2} \mathrm{H}_{6}$ by the TCD-gas chromatography as the water mole fraction of gas phase is negligibly small under the present experimental conditions.

\section{Raman Spectroscopic Analyses}

The gas mixture of $\mathrm{CH}_{4}$ and $\mathrm{C}_{2} \mathrm{H}_{6}$ prepared at a desired mole fraction was supplied into the evacuated high-pressure optical cell and then the proper quantity of water was introduced into the cell until the system pressure reached at the desired pressure. After the formation of gas hydrates, the system temperature was gradually risen to leave a few seed crystals and since then the system temperature was dropped little by little to prepare the single crystal of the hydrate under the three-phase (hydrate + water + gas) coexisting state. The single crystal was observed by use of the CCD camera through the sapphire window. Under the equilibrium state of three-phase coexistence, the single crystal of gas hydrate was analyzed through a sapphire window by in situ Raman spectroscopy using a laser Raman microprobe spectrophotometer with multichannel CCD detector. The argon ion laser beam (wavelength: $514.5 \mathrm{~nm}$, power: $100 \mathrm{~mW}$ ) from the object lens irradiated the sample through the upper sapphire window. The backscatter of the opposite direction was taken in with the same lens. The spectral resolution was about $1 \mathrm{~cm}^{-1}$.

\section{Estimation of Composition in the Hydrate Phase [8]}

The equilibrium composition in the mixed-gas hydrate phase $(z)$ can be estimated by mass and volume balances. The chemical formula of mixed-gas hydrate is generally written by $\left(1-z_{2}\right) \mathrm{CH}_{4} \bullet z_{2} \mathrm{C}_{2} \mathrm{H}_{6} \bullet q \mathrm{H}_{2} \mathrm{O}$, where $z_{2}$ is the mole fraction (water free) of $\mathrm{C}_{2} \mathrm{H}_{6}$ in the hydrate phase and $q$ denotes the hydration number of ideal gas-hydrate. The theory and equations of this analysis for the $\mathrm{CH}_{4}(1), \mathrm{C}_{2} \mathrm{H}_{6}(2)$, and water (3) were composed of six material-balances (from Eq. (1) to (6)) and one volume-balance (Eq. (7)) as follows:

$$
\begin{aligned}
& n_{1}{ }^{\mathrm{G}}+n_{1}{ }^{\mathrm{L}}+n_{1}{ }^{\mathrm{H}}=n_{1}{ }^{\mathrm{t}} \\
& n_{2}{ }^{\mathrm{G}}+n_{2}{ }^{\mathrm{L}}+n_{2}{ }^{\mathrm{H}}=n_{2}{ }^{\mathrm{t}} \\
& n_{3}{ }^{\mathrm{G}}+q\left(n_{1}{ }^{\mathrm{H}}+n_{2}{ }^{\mathrm{H}}\right)=n_{3}{ }^{\mathrm{t}} \\
& \left(1-y_{1}\right) n_{1}{ }^{\mathrm{G}}-y_{1} n_{2}{ }^{\mathrm{G}}=0 \\
& \left(1-x_{1}\right) n_{1}{ }^{\mathrm{L}}-x_{1} n_{2}{ }^{\mathrm{L}}-x_{1} n_{3}{ }^{\mathrm{L}}=0 \\
& \left(1-x^{{ }}{ }_{1}\right) n_{1}{ }^{\mathrm{L}}-x^{{ }}{ }_{1} n_{2}{ }^{\mathrm{L}}=0 \\
& v_{\text {mix }}{ }^{\mathrm{G}}\left(n_{1}{ }^{\mathrm{G}}+n_{2}{ }^{\mathrm{G}}\right)+v_{1}{ }^{\mathrm{L}} n_{1}{ }^{\mathrm{L}}+v_{2}{ }^{\mathrm{L}} n_{2}{ }^{\mathrm{L}} \\
& +v_{3}{ }^{\mathrm{L}} n_{3}{ }^{\mathrm{L}}+v^{\mathrm{H}} n_{1}{ }^{\mathrm{H}}+v^{\mathrm{H}} n_{2}{ }^{\mathrm{H}}=V \\
& z_{2}=n_{2}{ }^{\mathrm{H}} /\left(n_{1}{ }^{\mathrm{H}}+n_{2}{ }^{\mathrm{H}}\right)
\end{aligned}
$$

where $y$ and $x$ are equilibrium compositions of gas and aqueous (water free) phases, respectively, which can be obtained from gas chromatography. $v_{\text {mix }}{ }^{\mathrm{G}}$ is the molar volume of gas mixture, which can be calculated by Soave-RedlichKwong (SRK) equation of state [9]. $v_{1}^{\mathrm{L}}$ and $v_{2}^{\mathrm{L}}$ are partial molar volumes of $\mathrm{CH}_{4}$ and $\mathrm{C}_{2} \mathrm{H}_{6}$ in the aqueous phase at a given temperature, respectively, which were obtained from the reference [10]. $v_{3}{ }^{\mathrm{L}}$ is the molar volume of water. $v^{\mathrm{H}}$ is the molar volume of hydrate, which can be calculated by use of lattice constant of $1.20 \mathrm{~nm}$ (s-I) or $1.73 \mathrm{~nm}$ (s-II) [11]. The values of 5.75 and 5.67 are adopted as the $q$ of s-I and s-II, respectively, which are ideal hydration-number obtained on the assumption that all hydrate-cages are occupied by guest species. $V$ is the volume of high-pressure cell. The superscripts $\mathrm{H}, \mathrm{L}$, and $\mathrm{G}$ denote the hydrate phase, aqueous phase, and gas phase, respectively.

If it is assumed that the partial molar volume of $\mathrm{CH}_{4}$ dissolved in water $\left(v_{1}{ }^{\mathrm{L}}\right)$ was equal to that of infinite dilution at a given temperature, the apparent Henry constant of $\mathrm{CH}_{4}$ is evaluated from the data of vapor-liquid equilibrium before hydration occurs. The apparent Henry constant of $\mathrm{CH}_{4}, \mathrm{H}_{1}(\mathrm{~T}$, $p$ ) can be correlated as a function of temperature, $T$, and pressure, $p$ near the three-phase equilibrium line [8]. The $H_{1}(T, p)$ can be described as follows:

$H_{1}(T, p)=(1859-4.645 T / \mathrm{K}) \exp \left[v_{1}^{\mathrm{L}} / \mathrm{cm}^{3} \cdot \mathrm{mol}^{-1}(p / \mathrm{MPa}\right.$ $-7.285) \mathrm{K} / R T]$

where $R$ is the gas constant. As the volume of the equilibrium cell $(\mathrm{V})$ and the total amount of each component $\left(n_{1}{ }^{\mathrm{t}}\right.$, $n_{2}{ }^{\mathrm{t}}$, and $n_{3}{ }^{\mathrm{t}}$ ) were known, the mole fraction of $\mathrm{CH}_{4}$ in the aqueous phase, $x_{1}$, is obtainable at a given temperature and pressure as follows:

$x_{1}=f_{1}(T, p) / H_{1}(T, p)$ 
where $f_{1}(T, p)$ is the fugacity calculated from the equation of state recommended by IUPAC [12].

Table 1. Isothermal Phase Equilibria for the $\mathrm{CH}_{4}(1)+\mathrm{C}_{2} \mathrm{H}_{6}$ (2) Mixed-Gas Hydrate System Under three-Phase Equilibrium at 279.1, 283.1, and 288.1 K. The Symbols of $p$ and $T$ Stand for the Equilibrium Pressure and Temperature. The Symbols of $y, x$, and $z$ stand for the Equilibrium Composition in the Gas, Aqueous, and Hydrate Phases, Respectively. The $z_{2}$ (Quenched) Stands for the Equilibrium Composition of $\mathrm{C}_{2} \mathrm{H}_{6}$ in the Hydrate Phase Measured by Direct Dissociation Measurement. Blue and Green Columns Represent the s-I and s-II Hydrate Regions, Respectively

\begin{tabular}{|c|c|c|c|c|c|}
\hline$T / \mathbf{K}$ & $p / \mathrm{MPa}$ & $y_{2}$ & $x_{2}$ & $z_{2}$ & $z_{2}$ (Quenched) \\
\hline \multirow[t]{24}{*}{279.1} & 4.79 & 0.000 & 0.000 & 0.000 & \\
\hline & 3.83 & 0.027 & 0.0347 & 0.106 & \\
\hline & 3.54 & 0.038 & 0.132 & 0.170 & \\
\hline & 3.52 & 0.044 & 0.085 & 0.186 & \\
\hline & 3.33 & 0.050 & 0.068 & 0.205 & \\
\hline & 2.94 & 0.069 & 0.175 & 0.267 & \\
\hline & 2.74 & 0.081 & 0.131 & 0.309 & \\
\hline & 2.62 & 0.093 & 0.179 & 0.323 & \\
\hline & 2.45 & 0.116 & 0.170 & 0.359 & \\
\hline & 2.18 & 0.170 & 0.223 & 0.391 & \\
\hline & 2.13 & 0.186 & 0.229 & 0.390 & \\
\hline & 2.12 & 0.189 & 0.227 & 0.394 & \\
\hline & 1.92 & 0.211 & 0.337 & 0.407 & \\
\hline & 1.89 & 0.256 & 0.300 & 0.411 & \\
\hline & 1.62 & 0.385 & 0.434 & 0.684 & \\
\hline & 1.43 & 0.420 & 0.504 & 0.713 & \\
\hline & 1.43 & 0.474 & 0.528 & 0.713 & \\
\hline & 1.29 & 0.567 & 0.640 & 0.792 & \\
\hline & 1.23 & 0.582 & 0.654 & 0.796 & \\
\hline & 1.12 & 0.662 & 0.735 & 0.801 & \\
\hline & 1.01 & 1.000 & 1.000 & 1.000 & \\
\hline & 2.11 & 0.170 & & & 0.400 \\
\hline & 1.32 & 0.440 & & & 0.720 \\
\hline & 1.17 & 0.680 & & & 0.820 \\
\hline \multirow[t]{8}{*}{283.1} & 7.20 & 0.000 & 0.000 & 0.000 & \\
\hline & 6.00 & 0.035 & 0.082 & & \\
\hline & 5.35 & 0.051 & 0.108 & 0.196 & \\
\hline & 4.87 & 0.064 & 0.130 & & \\
\hline & 4.49 & 0.081 & 0.134 & & \\
\hline & 3.80 & 0.136 & 0.187 & 0.329 & \\
\hline & 3.66 & 0.169 & 0.248 & & \\
\hline & 3.59 & 0.197 & 0.261 & & \\
\hline
\end{tabular}

Table 1. Cont...

\begin{tabular}{|c|c|c|c|c|c|}
\hline$T / \mathbf{K}$ & $p / \mathrm{MPa}$ & $y_{2}$ & $x_{2}$ & $z_{2}$ & $z_{2}$ (Quenched) \\
\hline & 3.29 & 0.296 & 0.361 & & \\
\hline & 3.22 & 0.243 & 0.275 & 0.393 & \\
\hline & 3.09 & 0.300 & 0.379 & & \\
\hline & 3.05 & 0.316 & 0.361 & & \\
\hline & 2.79 & 0.350 & 0.382 & 0.586 & \\
\hline & 2.66 & 0.363 & 0.405 & & \\
\hline & 2.25 & 0.460 & 0.497 & 0.630 & \\
\hline & 2.01 & 0.518 & 0.572 & & \\
\hline & 1.98 & 0.575 & 0.600 & 0.747 & \\
\hline & 1.75 & 0.734 & 0.738 & 0.822 & \\
\hline & 1.66 & 0.871 & 0.871 & & \\
\hline & 1.69 & 1.000 & 1.000 & 1.000 & \\
\hline & 3.19 & 0.220 & & & 0.380 \\
\hline & 2.02 & 0.530 & & & 0.720 \\
\hline \multirow[t]{22}{*}{288.1} & 12.7 & 0.000 & 0.000 & 0.000 & \\
\hline & 12.3 & 0.009 & 0.009 & 0.044 & \\
\hline & 11.9 & 0.020 & 0.033 & 0.101 & \\
\hline & 10.3 & 0.038 & 0.063 & 0.182 & \\
\hline & 8.87 & 0.058 & 0.107 & 0.224 & \\
\hline & 8.36 & 0.067 & 0.109 & 0.265 & \\
\hline & 6.87 & 0.107 & 0.159 & 0.338 & \\
\hline & 6.43 & 0.157 & 0.193 & 0.361 & \\
\hline & 5.50 & 0.250 & 0.304 & 0.403 & \\
\hline & 4.98 & 0.342 & 0.379 & & \\
\hline & 4.86 & 0.349 & 0.397 & 0.441 & \\
\hline & 4.52 & 0.420 & 0.497 & 0.619 & \\
\hline & 4.14 & 0.473 & 0.518 & & \\
\hline & 4.02 & 0.483 & 0.537 & 0.690 & \\
\hline & 3.77 & 0.533 & 0.600 & 0.717 & \\
\hline & 3.63 & 0.603 & 0.643 & & \\
\hline & 3.36 & 0.663 & 0.705 & 0.836 & \\
\hline & 3.29 & 0.792 & 0.802 & 0.855 & \\
\hline & 3.27 & 0.898 & 0.881 & 0.869 & \\
\hline & 3.32 & 1.000 & 1.000 & 1.000 & \\
\hline & 5.70 & 0.250 & & & 0.370 \\
\hline & 3.37 & 0.680 & & & 0.760 \\
\hline
\end{tabular}

Finally, the seven unknown variables of $n_{1}{ }^{\mathrm{G}}, n_{2}{ }^{\mathrm{G}}, n_{1}{ }^{\mathrm{L}}, n_{2}{ }^{\mathrm{L}}$, $n_{3}{ }^{\mathrm{L}}, n_{1}{ }^{\mathrm{H}}$, and $n_{2}{ }^{\mathrm{H}}$ can be obtained from above simultaneous equations.

\section{RESULTS AND DISCUSSION}

The experimental data on the isothermal phase equilibrium (pressure - composition (water free)) relation for the $\mathrm{CH}_{4}+\mathrm{C}_{2} \mathrm{H}_{6}$ mixed-gas hydrate system at $279.1 \mathrm{~K}, 283.1 \mathrm{~K}$, 
and $288.1 \mathrm{~K}$ are summarized in Table $\mathbf{1}$ and shown in Fig. (1(a), (b), and (c)), respectively. In Fig. (1), the equilibrium compositions of gas and aqueous phases were measured by use of TCD-gas chromatography, while those of hydrate phase were estimated by mass and volume balances. The symbols of $x, y$, and $z$ stand for the equilibrium mole fraction of $\mathrm{C}_{2} \mathrm{H}_{6}$ in the aqueous, gas, and hydrate phases (water free) under the three-phase equilibrium conditions, respectively. In the present study, the mixed-gas hydrates prepared from gas mixtures at $279.1,283.1$, or $288.1 \mathrm{~K}$ under the threephase coexisting condition were quenched and taken out from the high-pressure cell at $253 \mathrm{~K}$. For this procedure, the excess water in the high-pressure cell was removed elaborately above the equilibrium pressure before quenching the hydrates. After dissociation of gas hydrate, gas sample was analyzed directly by use of the TCD-gas chromatography. These results are also summarized in Table $\mathbf{1}$ and Fig. (1). The mole fractions of hydrate phase by direct dissociation measurement agree well with those by the mass and volume balances.

The most characteristic behavior for the $\mathrm{CH}_{4}+\mathrm{C}_{2} \mathrm{H}_{6}$ mixed-gas hydrate system is the discontinuous variation of

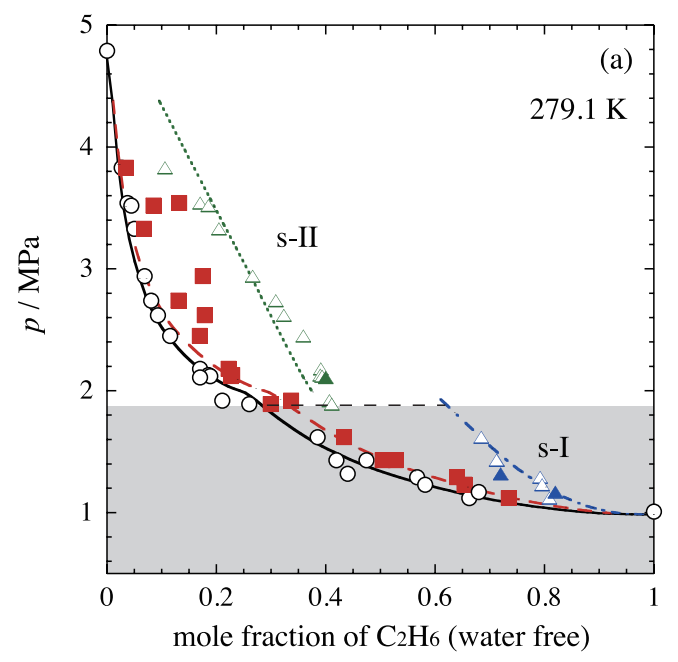

the equilibrium curve of hydrate phase at a certain composition region, which indicates the structural phase transition of mixed-gas hydrate. The detail conditions for the structural phase transition are summarized in Table 2 . The region of "composition jump" between s-I and s-II hydrates locates around $z_{2}=0.40-0.60$ at all temperatures. That is, the composition in the hydrate phase where the structural phase transition occurs would not depend on the system temperature under the present experimental temperature region. At 288.1 $\mathrm{K}$, we also succeed in obtaining the structural transition point of high-pressure $\left(\mathrm{CH}_{4}\right.$ rich) side. In addition, at 283.1 and $288.1 \mathrm{~K}$, the systems exhibit the negative azeotropic-like behavior in the $\mathrm{C}_{2} \mathrm{H}_{6}$-rich region [13]. In fact, at 283.1 K, we succeeded in finding the azeotropic point (1.66 MPa, $y_{2}=x_{2}$ $=0.871$ ). The three-phase (hydrate, gas, and aqueous phases) equilibrium point of pure $\mathrm{C}_{2} \mathrm{H}_{6}$ hydrate is close to the quadruple point. In the case of 279.1 and $283.1 \mathrm{~K}$, the equilibrium curve of each phase agrees with that from the simulation program (CSM Gem) by Sloan and Koh. [11]. Unfortunately, this simulation program cannot work successfully at $288.1 \mathrm{~K}$.
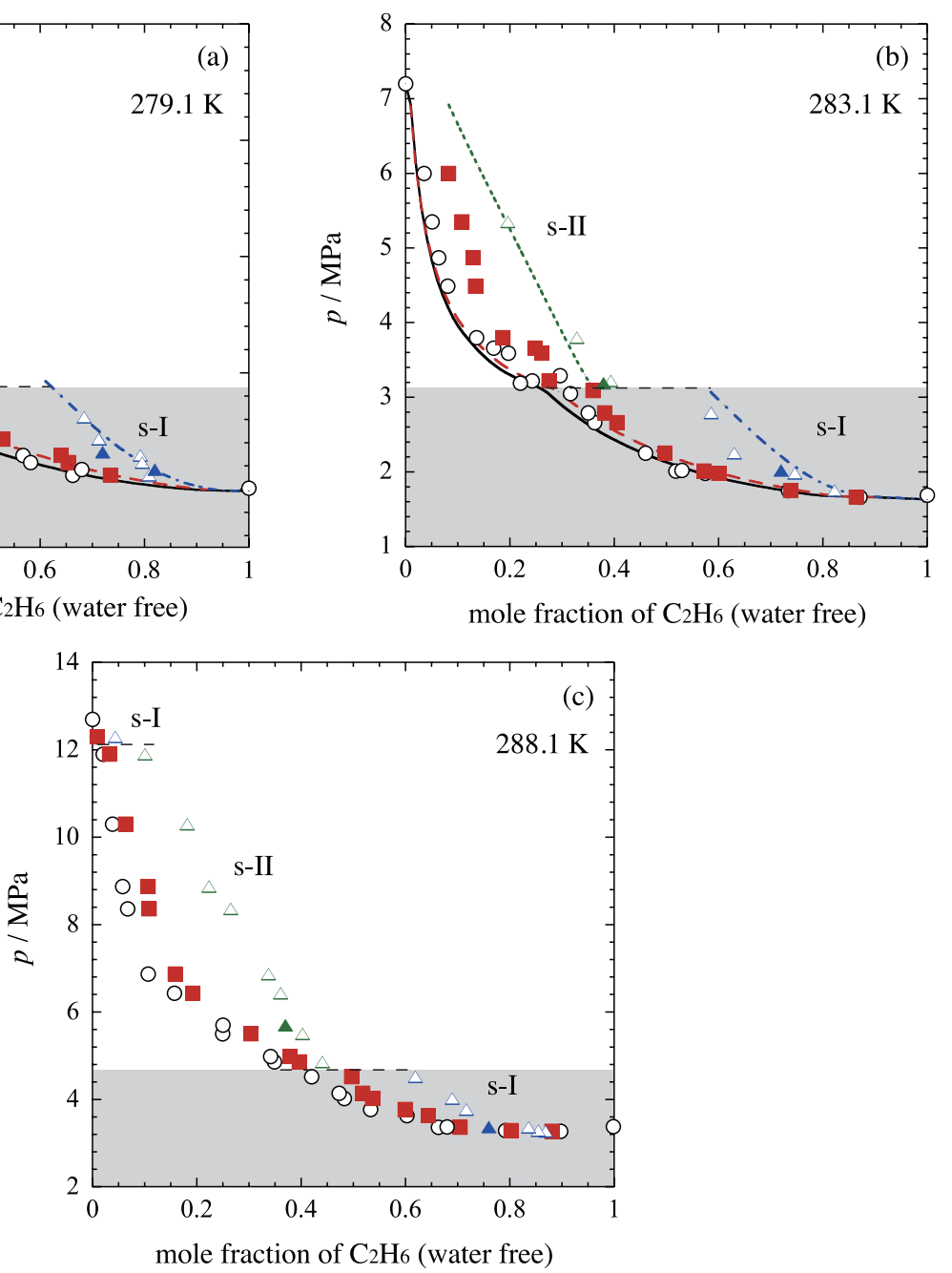

Fig. (1). Isothermal phase equilibrium (pressure - composition) relations for the $\mathrm{CH}_{4}+\mathrm{C}_{2} \mathrm{H}_{6}$ mixed-gas hydrate system at $279.1 \mathrm{~K}$ (a), 283.1

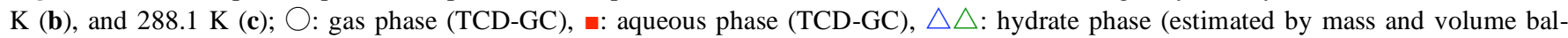
ances analysis), $\boldsymbol{\Delta} \boldsymbol{\Delta}$ : hydrate phase (quenched, TCD-GC). Blue and Green colors stand for the s-I and s-II regions, respectively. The curves represent the equilibrium relation obtained by CSM Gem [11]. The broken-horizontal lines represent the equilibrium pressure - composition relation at the structural transition point. 
Table 2. Conditions of Structural Phase Transition Between s-I and s-II for the $\mathrm{CH}_{4}+\mathrm{C}_{2} \mathrm{H}_{6}$ Mixed-Gas Hydrate System. Table Contains the Data Calculated by CSM Gem [11]

\begin{tabular}{|c|c|c|c|}
\hline $\boldsymbol{T} / \mathbf{K}$ & $\boldsymbol{p} / \mathbf{M P a}$ & $\boldsymbol{y}_{\mathbf{2}}$ & $\boldsymbol{z}_{\mathbf{2}}(\mathbf{s}-\mathbf{I I}-\mathbf{s}-\mathbf{I})$ \\
\hline \hline 279.1 & 1.82 & 0.25 & $0.40-0.60$ \\
\hline CSM Gem & 1.95 & 0.26 & $0.38-0.61$ \\
\hline 283.1 & 3.01 & 0.32 & $0.40-0.57$ \\
\hline CSM Gem & 3.10 & 0.26 & $0.36-0.58$ \\
\hline 288.1 & 4.70 & 0.40 & $0.43-0.58$ \\
\hline
\end{tabular}

Fig. (2) shows phase equilibrium (pressure - temperature) relation for the $\mathrm{CH}_{4}+\mathrm{C}_{2} \mathrm{H}_{6}$ mixed-gas hydrate system. As shown in Fig. (2), the three-phase equilibrium pressures increase monotonically as temperature increases. Under the present experimental condition, the three-phase equilibrium curves of $\mathrm{CH}_{4}+\mathrm{C}_{2} \mathrm{H}_{6}$ mixed-gas hydrate would not intersect that of pure $\mathrm{CH}_{4}$ hydrate, opposed to the previous data [14]. The structural transition points obtained in the present study agree with those reported by Subramanian, Kini, Dec and Sloan [1].

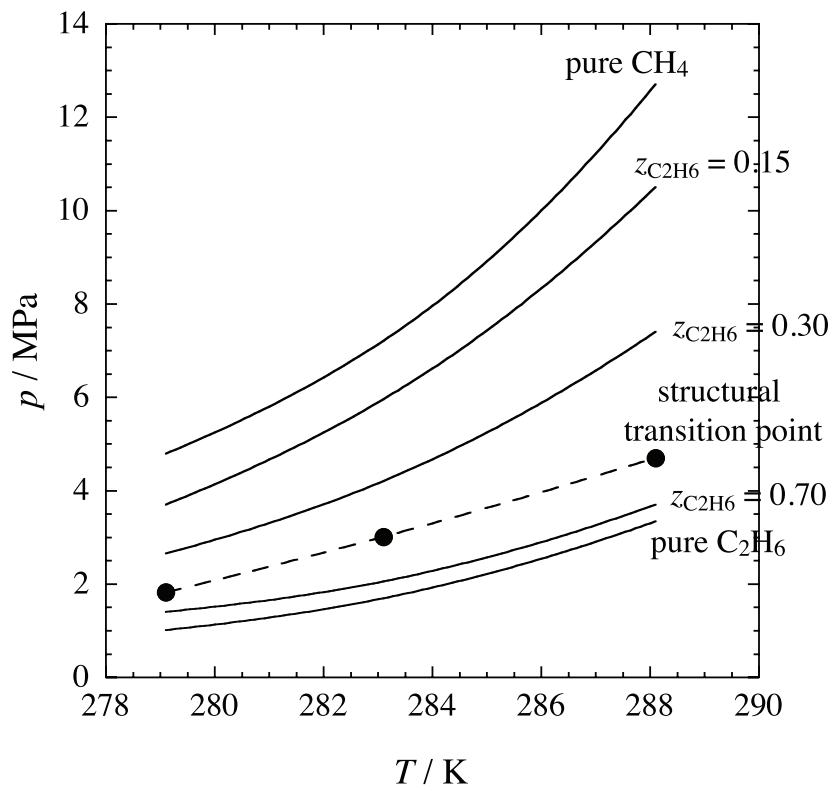

Fig. (2). Phase equilibrium (pressure - temperature) relations for the $\mathrm{CH}_{4}+\mathrm{C}_{2} \mathrm{H}_{6}$ mixed-gas hydrate system; $\mathrm{O}$ : structural phase transition points.

In the present study, the structure of the $\mathrm{CH}_{4}+\mathrm{C}_{2} \mathrm{H}_{6}$ mixed-gas hydrate was investigated at $279.1 \mathrm{~K}$ by in-situ Raman micro-spectroscopy. Typical Raman spectra of $\mathrm{CH}_{4}$ and $\mathrm{C}_{2} \mathrm{H}_{6}$ in the gas and hydrate phases are shown in Figs. (3) and (4). The symbol of $z$ in Figs. (3) and (4) stands for the equilibrium composition of $\mathrm{C}_{2} \mathrm{H}_{6}$ in the hydrate phase (water free) under the three-phase equilibrium conditions. Fig. (3) shows the Raman spectra derived from $\mathrm{C}_{2} \mathrm{H}_{6}$ at $279.1 \mathrm{~K}$. In the hydrate phase, each peak is derived from the C-C stretching vibration of the $\mathrm{C}_{2} \mathrm{H}_{6}$ molecule that is enclathrated in the large cage. The $\mathrm{C}_{2} \mathrm{H}_{6}$ molecule cannot occupy the $\mathrm{S}$-cages in the relatively low-pressure region of the present study because of their larger van der Waals diameter than the free volume of S-cage [11]. The Raman peak corresponding to the symmetric C-C stretching vibration of $\mathrm{C}_{2} \mathrm{H}_{6}$ is detected at $995 \mathrm{~cm}^{-1}$ in the gas phase. In the hydrate phase (region A), the characteristic Raman peak of the symmetric C-C stretching vibration of $\mathrm{C}_{2} \mathrm{H}_{6}$ is obtained at $1001 \mathrm{~cm}^{-1}$, which is similar to the peak of $\mathrm{C}_{2} \mathrm{H}_{6}$ in the M-cage of s-I hydrate $[1,15]$. On the other hand, it is detected at $992 \mathrm{~cm}^{-1}$ in the hydrate phase (region $\mathrm{B}$ ), which agrees well with the peak of $\mathrm{C}_{2} \mathrm{H}_{6}$ in the L-cage of s-II hydrate [1]. That is, Fig. (3) indicates that the $\mathrm{CH}_{4}+\mathrm{C}_{2} \mathrm{H}_{6}$ gas mixture constructs the $\mathrm{s}-\mathrm{I}$ hydrate in the region $\mathrm{A}$, while the s-II hydrate in the region B.

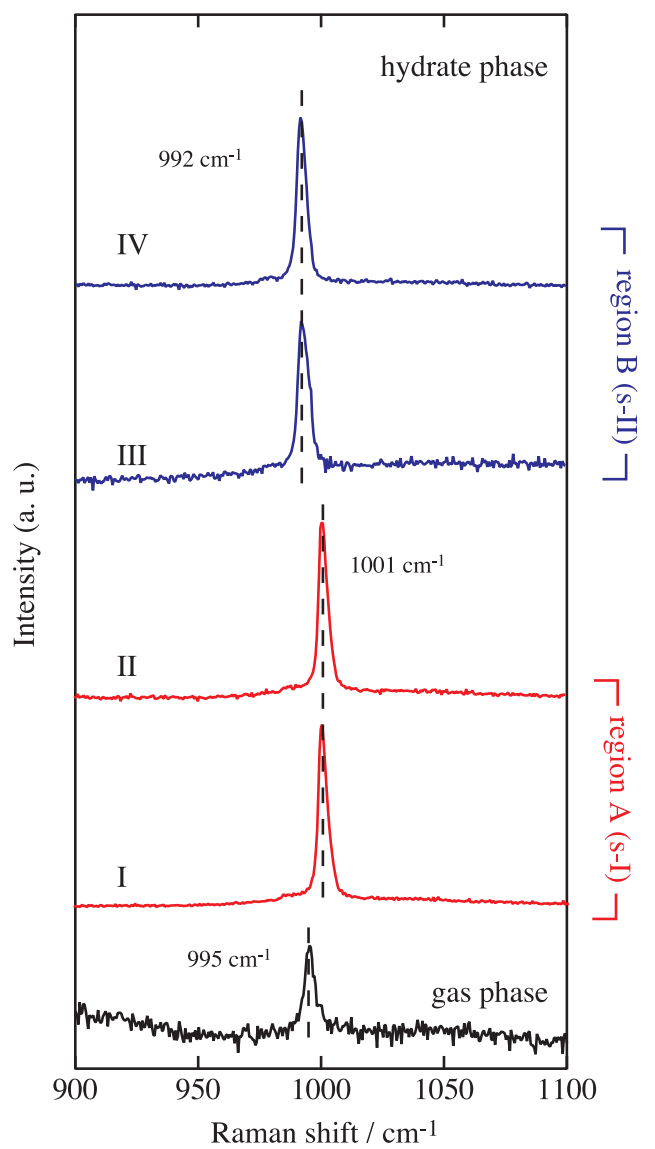

Fig. (3). Raman spectra derived from the intramolecular $\mathrm{C}-\mathrm{C}$ stretching vibration of $\mathrm{C}_{2} \mathrm{H}_{6}$ for the $\mathrm{CH}_{4}+\mathrm{C}_{2} \mathrm{H}_{6}$ mixed-gas hydrate system at $279.1 \mathrm{~K}$; in the hydrate phase, I: $1.50 \mathrm{MPa}, z_{2}=0.71$, II: $1.70 \mathrm{MPa}, z_{2}=0.61$, III: $2.30 \mathrm{MPa}, z_{2}=0.37$, IV: $2.60 \mathrm{MPa}, z_{2}=$ 0.31 .

Fig. (4) shows the Raman peaks corresponding to symmetric C-H stretching vibration mode of $\mathrm{CH}_{4}$ and $\mathrm{C}_{2} \mathrm{H}_{6}$ molecules obtained in the gas and hydrate phases at $279.1 \mathrm{~K}$. In the gas phase, the peak of $\mathrm{CH}_{4}$ is detected at $2917 \mathrm{~cm}^{-1}$, while the doublet peak of $\mathrm{C}_{2} \mathrm{H}_{6}$ resulting from Fermi resonance effect is obtained around 2900 and $2955 \mathrm{~cm}^{-1}$. This resonance effect is caused by anharmonic coupling between the symmetric $\mathrm{C}-\mathrm{H}$ stretching vibration mode $\left(v_{1}\right)$ and an overtone mode of one of the $\mathrm{CH}_{3}$ deformation vibrations $\left(2 v_{2}\right)$ [16]. In the hydrate phase (region A), the doublet peak derived from $\mathrm{CH}_{4}$ is detected at 2904 and $2915 \mathrm{~cm}^{-1}$, which corresponds to the $\mathrm{CH}_{4}$ molecule enclathrated in the $\mathrm{M}$ - and $\mathrm{S}$-cages of $\mathrm{s}-\mathrm{I}$ hydrate, respectively. The doublet peak of $\mathrm{C}_{2} \mathrm{H}_{6}$ enclathrated in the M-cage is detected around 2891 and $2946 \mathrm{~cm}^{-1}$. On the other hand, in the region $\mathrm{B}$, the peaks of 
$\mathrm{CH}_{4}$ are obtained at 2903 (corresponds to the $\mathrm{CH}_{4}$ enclathrated in the L-cage) and $2915 \mathrm{~cm}^{-1}$ and the intensity ratio of two peaks is reversed between the regions $\mathrm{A}$ and $\mathrm{B}$. The peaks of $\mathrm{C}_{2} \mathrm{H}_{6}$ enclathrated in the L-cage are detected around 2886 and $2940 \mathrm{~cm}^{-1}$ in the region B. All results of Raman spectroscopic measurements obtained in the present study agree well with those of Subramanian, Kini, Dec and Sloan [1].

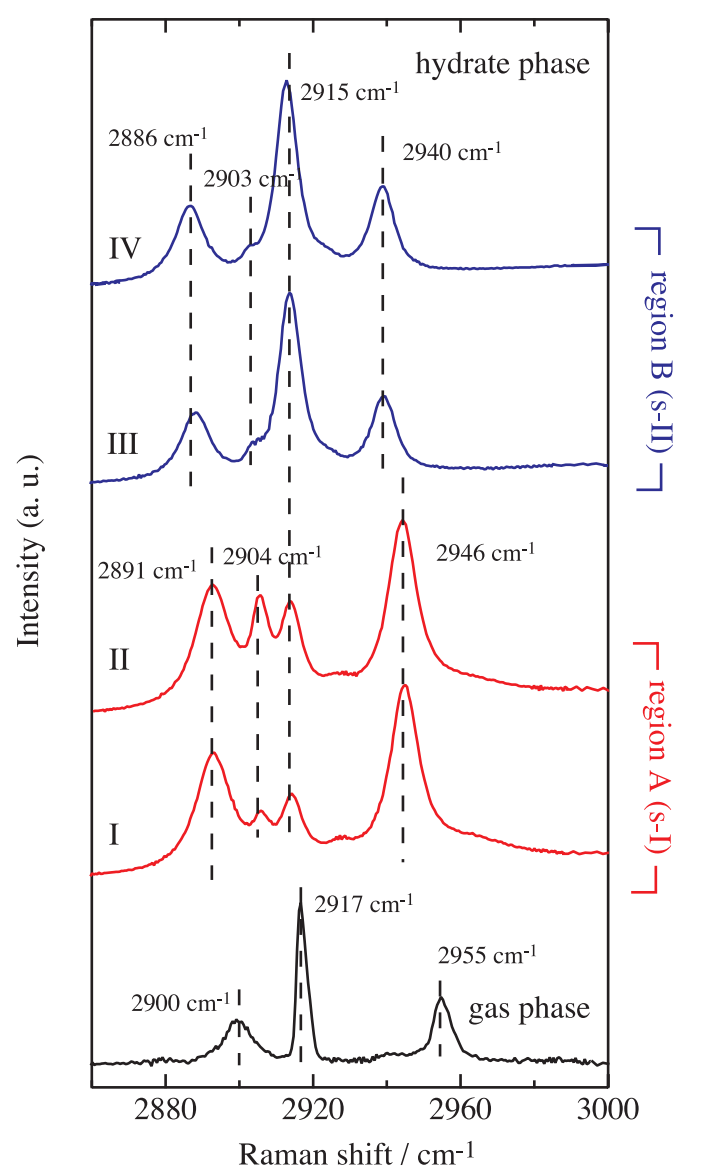

Fig. (4). Raman spectra derived from the intramolecular $\mathrm{C}-\mathrm{H}$ stretching vibration of $\mathrm{CH}_{4}$ and Fermi resonance peak of $\mathrm{C}_{2} \mathrm{H}_{6}$ for the $\mathrm{CH}_{4}+\mathrm{C}_{2} \mathrm{H}_{6}$ mixed-gas hydrate system at 279.1 K. All labels correspond to those of Fig. (3).

\section{CONCLUSIONS}

Isothermal phase equilibria for the $\mathrm{CH}_{4}+\mathrm{C}_{2} \mathrm{H}_{6}$ mixedgas hydrate system were measured at $279.1 \mathrm{~K}-288.1 \mathrm{~K}$. We focused attention on the composition of hydrate phase and the phase behavior around the structural transition points. We confirmed the hydrate structural-transition at all temperature conditions, just as Subramanian, Kini, Dec and Sloan already [1]. The pressure of structural transition point increases monotonically as temperature rises, and the mole fractions (water free) of hydrate phase at the structural transition point are 0.40 (s-II) and 0.60 (s-I) under the whole experimental temperature region.

\section{ACKNOWLEDGEMENTS}

This work was financially supported from Japan National Oil Corporation and Mitsui Engineering \& Shipbuilding, Co, Ltd. S. Hashimoto shows his gratitude for the center of excellence (COE) program of Osaka University. We gratefully acknowledge the Division of Chemical Engineering, Graduate School of Engineering Science, Osaka University for the scientific support by "Gas-Hydrate Analyzing System (GHAS)".

\section{REFERENCES}

[1] S. Subramanian, R. A. Kini, S. F. Dec, and E. D. Sloan Jr., "Evidence of Structure II Hydrate Formation from Methane + Ethane Mixtures", Chem. Eng. Sci., vol. 55, pp. 1981-1999, June 2000.

[2] S. Subramanian, A. L. Ballard, R. A. Kini, S. F. Dec, and E. D. Sloan Jr., "Structural Transitions in Methane + Ethane Gas Hydrates - Part I: Upper Transition Point and Applications", Chem. Eng. Sci., vol. 55, pp. 5763-5771, June 2000.

[3] A. L. Ballard, and E. D. Sloan Jr., "Structural Transitions in Methane + Ethane Gas Hydrates - Part II: Modeling Beyond Incipient Conditions", Chem. Eng. Sci., vol. 55, pp. 5773-5782, June 2000.

[4] T. Makino, M. Tongu, T. Sugahara, and K. Ohgaki, "Hydrate Structural Transition Depending on the Composition of Methane + Cyclopropane Mixed Gas Hydrate", Fluid Phase Equilib., vol. 233, pp. 129-133, June 2005.

[5] Y. Kunita, T. Makino, T. Sugahara, and K. Ohgaki, "Raman Spectroscopic Studies on Methane + Tetrafluoromethane Mixed-Gas Hydrate System", Fluid Phase Equilib., vol. 251, pp. 145-148 February 2007.

[6] T. Sugahara, T. Makino, and K. Ohgaki, "Isothermal Phase Equilibria for the Methane + Ethylene Mixed Gas Hydrate System", Fluid Phase Equilib., vol. 206, pp. 117-126, April 2003.

[7] S. Nakano, M. Moritoki, and K. Ohgaki, "High-pressure Phase Equilibrium and Raman Microprobe Spectroscopic Studies on the $\mathrm{CO}_{2}$ Hydrate System", J. Chem. Eng. Data, vol. 43, pp. 807-810, September 1998.

[8] K. Ohgaki, K. Takano, H. Sangawa, T. Matsubara, and S. Nakano, "Methane Exploitation by Carbon Dioxide From Gas Hydrates Phase Equilibria for $\mathrm{CO}_{2}-\mathrm{CH}_{4}$ Mixed Hydrate System -", J. Chem. Eng. Japan, vol. 29, pp. 478-483, June 1996.

[9] G. Soave, "Equilibrium Constants from a Modified Redlich Kwong Equation of State", Chem. Eng. Sci., vol. 27, pp. 11971203, June 1972.

[10] E. W. Lyckman, C. A. Ecker, and J. M. Praushnitz, "Generalized Reference Fugacities for Phase Equilibrium Thermodynamics", Chem. Eng. Sci., vol. 20, pp. 685-691, July 1965.

[11] E. D. Sloan and C. A. Koh, "Clathrate Hydrate of Natural Gases, $3^{\text {rd }}$ ed.", Boca Raton: CRC Press, September 2007.

[12] A. Angus, B. Armstrong, and K. M. de Reuck, "International Thermodynamic Tables of the Fluid State Methane", Pargamon Press, Oxford, 1976.

[13] G. D. Holder, and G. C. Grigoriou, "Hydrate Dissociation Pressures of (Methane + Ethane + Water) Existence of a Locus of Minimum Pressures", J. Chem. Thermodynamics, vol. 12, pp. 1093-1104, November 1980.

[14] H. O. McLeod, and J. M. Campbell, "Natural Gas Hydrates at pressures to 10,000 psia", J. Petrol. Technol., vol. 13, pp. 590-594, June 1961

[15] K. Morita, S. Nakano, and K. Ohgaki, "Structure and Stability of Ethane Hydrate Crystal", Fluid Phase Equilib., vol. 169, pp. 167175, March 2000.

[16] Z. Herzberg, "Infrared and Raman Spectra, Fifth Printing", New York: D. von Nostrand Company Inc., 1951. 